\title{
A ARTE COMO MODO DE CONSIDERAÇÃO INDEPENDENTE DO PRINCÍPIO DE RAZÃO
}

RESUMO: O presente artigo tem por objetivo explicitar a concepção de puro sujeito do conhecimento e a concepção de gênio enquanto fundamentos da arte na filosofia de Arthur Schopenhauer. A arte é concebida pelo filósofo como modo de conhecimento independente do princípio de razão. Se a representação que segue o princípio de razão é válida para ciência, a representação que prescinde desse princípio atua na arte. Por isso a arte como modo próprio de conhecer se distingue da ciência, visto ser uma forma de conhecimento que ergue o homem acima do indivíduo. Ao elevar o homem, arte proporciona um conhecimento puro que propicia um descanso momentâneo das intempéries da existência. Ocorre que, esse conhecimento puro é apreendido e sua posse pertence ao que Schopenhauer chamou de puro sujeito do conhecer. No puro sujeito do conhecer, encontra-se o artista, mas não o artista comum, e sim uma categoria muito particular: o gênio, pois é a ideia que ele almeja e, sua manifestação é exclusivamente artística. O puro sujeito do conhecimento possui duas acepções: (i) a primeira enquanto artista ou gênio; e (ii) enquanto espectador da obra de arte. Nesse artigo buscaremos analisar essas duas acepções dentro da concepção de arte de Schopenhauer.

Palavras-chave: Arte; Puro sujeito do conhecimento; Gênio.

\section{ART AS A MODE OF CONSIDERATION INDEPENDENT OF THE PRINCIPLE OF REASON}

\begin{abstract}
The present study aims to explain the concept of pure subject of knowledge and the concept of genius while foundations of art in Arthur Schopenhauer's philosophy. Art is conceived by the philosopher as a mode of knowledge independent of the principle of reason. If the representation that follows the principle of reason is valid for science, the representation that dispenses with this principle works in art. Therefore, art as a proper way of knowing is distinguished from science, as it is a form of knowledge that raises man above the individual. By elevating man, art provides a pure knowledge that provides a momentary respite from the storms of existence. It so happens that this pure knowledge is apprehended and its possession belongs to what Schopenhauer called the pure subject of knowing. In the pure subject of knowing, there is the artist, but not the common artist, but a very particular category: the genius, as it is the idea he craves and its manifestation is exclusively artistic. The pure subject of knowledge has two meanings: (i) the first while an artist or genius; and (ii) as a spectator of the artwork. In this article, we will analyze these two meanings within Schopenhauer's conception of art.
\end{abstract}

Keywords: Art; Pure subject of knowledge; Genius.

${ }^{1}$ Universidade Estadual do Oeste Do Paraná (UNIOESTE) Departamento de filosofia. Area: Metáfisica e conhecimento. E-mail: caiomiguel79@ outlook.com 


\section{INTRODUÇÃO}

A compreensão de arte possui um lugar de destaque na filosofia de Schopenhauer. Para o filósofo, a arte se configura como um modo particular de conhecer, que a rigor se distingue do conhecimento proporcionado pela ciência. Se a representação que segue o princípio de razão é válida para ciência, a representação que prescinde desse princípio atua na arte. Por isso a arte como modo próprio de conhecer se distingue da ciência, visto ser uma forma de conhecimento que proporciona a condição de um puro conhecer, independente do princípio de razão. Acontece que o saber artístico comunica a ideia, motivo pelo qual exprime o essencial do mundo em via oposta ao conhecer da ciência que, a saber, no "sentido próprio do termo é compreendido como conhecimento sistemático guiado pelo fio condutor da razão" (SCHOPENHAUER, 2005, p. 73). De forma mais específica, a arte é domínio do conhecimento que manifesta o belo, bem como “o essencial propriamente dito do mundo, alheio e independente de toda a relação, o conteúdo verdadeiro das aparências, não submetidos à mudança alguma e, por conseguinte, conhecido como igual verdade por todo o tempo, numa palavra, as IDEIAS” (SCHOPENHAUER, 2005, p.253).

A arte exprime o conteúdo verdadeiro das representações, isto é, a ideia grau de objetidade imediata adequada da vontade. Na contemplação artística é desvelada a ideia dos fenômenos na sua forma intuitiva, do mesmo modo que ela "repete em suas obras as Ideias apreendidas por pura contemplação" (SCHOPENHAUER, 2003, p.58). Assim, a arte se configura como modo de conhecer contemplativo, pois o "objeto de sua contemplação ela retira da torrente do curso do mundo e isola diante de si" (SCHOPENHAUER, 2005, p.253). Uma vez que extrai das coisas do mundo o essencial, a arte é por si mesma o modo de conhecimento distinto. Ela apreende o conteúdo verdadeiro, a ideia una e atemporal. Nesse sentido a arte se detém no essencial, "nesse particular, a roda do tempo para; as relações desaparecem para ela. Apenas o essencial, a ideia é o seu objeto" (SCHOPENHAUER, 2003, p.59).

Do exposto, é possível compreender que na arte "há um momento privilegiado, iluminado e redentor, em que consideramos a essência das coisas" (BARBOZA, 1997, p.58). Pode-se dizer, ademais, que na arte, na calma contemplação da ideia, somos 
embevecidos pela paz e pela sensação de tranquilidade nos encanta. A arte, nesse sentido, é um modo de conhecimento que proporciona a momentânea suspenção da vontade, na medida em que, na pura contemplação da ideia, somos libertos da vontade. Em outros termos, apenas "pela pura contemplação a dissolver-nos completamente no objeto é que as ideias são apreendidas" (SCHOPENHAUER, 2005, p.254).

Para Cacciola, comentando esse aspecto da filosofia de Schopenhauer: "arte não trata de representar o mundo fenomênico, mas a representação, ao se referir à ideia, desloca-se do múltiplo aprendido pelo entendimento, por meio do espaço, tempo e causalidade, para o uno intemporal" (CACCIOLA, 1999, p.9). Por isso, a arte exprime uma forma de conhecimento que, por sua vez, ocorre de maneira distinta. De fato, a compreensão schopenhaeuriana eleva a arte a outra condição, visto que exprime um conhecimento puro. Esse conhecimento puro é apreendido e sua posse pertence ao que Schopenhauer chamou de puro sujeito do conhecer.

\section{O PURO SUJEITO DO CONHECIMENTO DESTITUÍdO DE VONTADE E SOFRIMENTO}

De acordo com Schopenhauer, o puro sujeito do conhecer "sem subjetividade considera as coisas de modo puramente objetivo, por inteiro entregue a elas, as quais estão na consciência só na medida em que são meras representações, não motivos" (SCHOPENHAUER, 2003, p.91-92). No conhecer de modo puramente objetivo ocorre que o indivíduo se liberta do jugo da vontade. Por meio dessa "tal libertação do conhecimento sobreleva-nos de forma tão completa quanto o sono e o sonho: felicidade e infelicidade desaparecem" (SCHOPENHAUER, 2005, p.266). Assim, Schopenhauer descreve o estado de paz momentânea proporcionado pela apreensão da ideia no puro conhecimento proporcionado pelo artista em sua obra de arte.

Ora, nesse sentido, o puro conhecimento é um conhecimento mais elevado, pois, ao contrário do conhecimento individual, não serve à vontade. Se, no conhecimento submetido ao princípium individuationis, a vontade é manifesta no indivíduo, no conhecimento puro a vontade é destituída. Como salienta o próprio Schopenhauer: "o puro conhecimento destituído de vontade é alcançado na medida em que a consciência das outras coisas potencia-se tão elevadamente que desaparece a consciência do próprio 
si mesmo" (SCHOPENHAUER, 2015, p.440). Com efeito, se no conhecimento individual há apenas apreensão das coisas isoladas, no conhecimento puro ocorre a apreensão ideacional das coisas do mundo. Por isso, Schopenhauer propõe que o indivíduo ascende à condição de sujeito puro, justamente porque não conhece mais os objetos do mundo de acordo com sua temporalidade e espacialidade, ou seja, a partir de sua individualidade, mas sim de acordo com a ideia enquanto grau de objetidade determinado da vontade. Desse modo, puro sujeito e ideia são elementos simultâneos no ato de conhecer. Aqui se trata de perceber que há uma mudança substancial nos componentes do conhecimento no ato de contemplação. Segundo Schopenhauer:

Em tal contemplação, de um só golpe a coisa particular se torna a IDEIA de sua espécie e o indivíduo que intui se torna PURO SUJEITO DO CONHECER. $\mathrm{O}$ indivíduo enquanto tal conhece apenas as coisas isoladas; o puro sujeito do conhecer, somente Ideias (SCHOPENHAUER, 2005, p.247).

Schopenhauer explicita que o indivíduo tem acesso à condição de puro sujeito do conhecimento na medida em que contempla a ideia. Assim, no ato contemplativo, ocorre uma apreensão ideacional, visto que o saber da ideia proporciona a superação do conhecimento das representações submetidas às relações do espaço e do tempo. Nesse domínio do conhecer contemplativo, o indivíduo destitui-se de sua vontade, isto é, libertase da vontade por meio de uma plena liberdade e tranquilidade espiritual: um "desfazerse na intuição", um esquecer-se de toda a individualidade (cf. BARBOZA, 2005, p.229). Enquanto liberto da vontade, o indivíduo se perfaz no puro sujeito do conhecer, e na medida em que é absorvido na pura intuição livre, torna-se, ao mesmo tempo, livre do querer dos objetos e independente do princípio de razão.

Schopenhauer descreve a passagem do indivíduo ao puro sujeito do conhecer, isto é, quando há suspenção do querer individual a uma paz momentânea proporcionada pela contemplação da ideia. De acordo com o filósofo, no exato momento do conhecimento puro, o sujeito não é mais submetido aos motivos ou propósitos da vontade. Certamente, isso ocorre devido à transição do conhecimento comum das coisas para o conhecimento puro da ideia. Em linhas gerais, nessa transição, ocorre uma mudança do conhecer individual submetido ao princípio de razão e ao princípium individuationis para o âmbito puro, no qual o puro sujeito e ideia são componentes necessários. Por ser contrário ao 
conhecimento servil da vontade, o conhecimento puro é extraordinário, já que exprime uma forma de conhecer elevada. Nesse sentido:

\begin{abstract}
Quando, elevados pela força do espírito, nós deixamos de lado o modo comum de consideração das coisas, cessamos de seguir suas relações mútuas conforme o princípio de razão, cujo fim último é sempre a relação com a própria vontade; logo, quando não mais consideramos o Onde, o Quando, o Porquê e o Para Quê das coisas, mas única exclusivamente o seu Quê; noutros termos, quando o pensamento abstrato, os conceitos da razão não mais tomam conta da consciência, mas, em vez disso, todo o poder do espírito é devotado à intuição, afundando-nos completamente nesta, e a consciência inteira é preenchida pela calma contemplação do objeto natural que acabou de se apresentar, seja uma paisagem, uma árvore, um penhasco, uma construção ou outra coisa qualquer; quando, conforme uma significativa expressão germânica, a gente se PERDE por completo nesse objeto, isto é, esquece o próprio indivíduo, a própria vontade, e permanece apenas como claro espelho do objeto: então é como se apenas o objeto ali existisse, sem alguém que o percebesse, não se pode separar quem intui da intuição, mas ambos se tornam unos, na medida em que toda consciência é integralmente preenchida e tomada por uma única imagem intuitiva (SCHOPENHAUER, 2005, p.246).
\end{abstract}

Em conformidade com o pensamento de Schopenhauer, ao elevarmo-nos da forma comum do conhecer das coisas, por meio de um saber independente do princípio de razão, deixamos de conhecer as coisas de acordo com suas relações submetidas à vontade e ao sofrimento. Mas não apenas isso, pois, quando somos tomados pela força da consciência pura de si, bem como pela simultânea objetidade imediata da vontade, renunciamos a todo querer de acordo com um puro conhecimento. Trata-se então de um domínio do conhecer que se liberta das relações de um conhecer subordinado ao princípio de razão, assim como de uma individualidade que serve à vontade em seu ímpeto cego de um querer incessante.

De acordo com o filósofo, no âmbito do conhecer contemplativo, não consideramos mais o ONDE, isto é, a esfera do espaço e sua relação de espacialidade, tampouco o QUANDO de acordo com sua temporalidade concebida em sua sucessão temporal. As relações de causalidade e finalidade concebidas no modo comum de conhecer as coisas que se encontram submetidas ao princípio de razão e, com efeito, subordinadas à vontade, são suspendidas no ato intuitivo e contemplativo. Por isso, Schopenhauer enfatiza que conhecemos única e exclusivamente o QUÊ da coisa, isto é, seu grau de objetidade da vontade determinado, que, a saber, encontra-se na intuição pura da plena contemplação na forma da ideia. Nesse sentido, os conceitos abstratos, assim como o querer incessante da vontade, são suspendidos pela força do espírito, isso porque 
a consciência pura se PERDE (verliert) na ideia apreendida. Desse modo ainda, a intuição e quem a intui se tornam um só na medida em que se configuram como uma só imagem intuitiva. Schopenhauer descreve em outro registro a forma pura e objetiva do perder-se por completo no objeto:

\begin{abstract}
É uma maneira germânica de falar plena de sentido a de que nos perdemos por completo num objeto, ou seja, perdemos de vista justamente o próprio indivíduo, a própria vontade: a disposição se torna puramente objetiva: toda a consciência é ainda apenas o espelho claro do objeto oferecido, é o medium pelo qual este entra em cena no mundo como representação. Sabemos de nós mesmos apenas na medida em que sabemos do objeto: ainda permanecemos aí tão-somente como puro sujeito do conhecer. Ainda sabemos, por um instante, que algo aqui é intuído, mas não sabemos mais quem intui: toda a consciência é integramente preenchida e tomada por uma única imagem intuitiva (SCHOPENHAUER, 2003, p.46).
\end{abstract}

Para Schopenhauer, na intuição "há um "deixar-se levar" pela contemplação. Esse “deixar-se levar" é "a pura objetidade da intuição"” (SCHOPENHAUER, 2015, p. 442), modo pelo qual o intelecto apreende a forma da coisa intuída em uma única imagem intuitiva. Essa imagem intuitiva é eterna, imóvel e simultaneamente inteligível, "é condicionada pelo fato de o contemplador não estar mais consciente de si mesmo, mas exclusivamente dos objetos intuídos" (SCHOPENHAUER, 2015, p.442). No conhecer puramente objetivo, o sujeito "se abandona por inteiro no objeto intuído, tornou-se objeto mesmo, a consciência inteira nada mais é senão sua imagem nítida, é apenas um medium para entrada em cena do objeto no mundo da representação" (SCHOPENHAUER, 2003, p.48).

Além disso, no conhecer puramente objetivo, ocorre uma unidade entre puro sujeito do conhecer e ideia. Por isso, percebemos que a mudança do indivíduo ocorre concomitantemente com a mudança do conhecimento das coisas particulares. É no intuir da ideia que ocorre uma plenitude do conhecimento. Na forma plena de conhecer, a coisa particular se torna ideia e o indivíduo, puro sujeito do conhecer. E, nesse esquema, enquanto o indivíduo conhece apenas as coisas isoladas do mundo que se encontram no espaço e no tempo de acordo com as determinações do princípio de razão e de individuação, o puro sujeito conhece a ideia independente desses princípios na forma eterna e atemporal. Por isso Schopenhauer sustenta que: 
Encontramos no modo de conhecimento estético DOIS COMPONENTES INSEPARÁVEIS: Primeiro o conhecimento do objeto não como coisa isolada, mas como IDEIA platônica, ou seja, como forma permanente de todo esse gênero de coisas, depois a consciência de si daquele que conhece, não como indivíduo, mas como PURO SUJEITO DO CONHECIMENTO DESTÍTUIDO DE VONTADE (SCHOPENHAUER, 2005, p.265,266).

Em consonância com a citação acima, percebe-se que o puro sujeito do conhecimento tem a ideia como correspondente necessário na intuição. Assim, são dois os componentes dessa forma de conhecimento. O primeiro componente consiste na ideia enquanto consideração objetiva do conhecer. Já o segundo componente consiste no puro sujeito do conhecimento na qualidade de consideração subjetiva do conhecer. Ora, esses dois componentes são inseparáveis, na razão de serem a condição da elevação do conhecimento das coisas particulares ao conhecimento puro proporcionado pela contemplação do belo. Ademais, ideia e puro sujeito do conhecimento estão circundados por um modo específico do conhecer humano explicitado por Schopenhauer em seu Livro III de $O$ Mundo. Esse modo específico de conhecer é a arte.

De fato, a compreensão schopenhaeueriana eleva a arte a outra condição, visto que exprime um conhecimento puro. Esse conhecimento puro é apreendido e sua posse pertence ao puro sujeito do conhecer. E como fora explicitado acima, o puro sujeito do conhecer é um dos fundamentos do conhecer estético. Como fundamento do conhecer estético, o puro sujeito é aquele que apreende a ideia, seja como artista de gênio ou espectador: a ideia é contemplada e exposta na forma de arte. Trataremos dessa passagem da ideia apreendida pelo artista ao espectador a partir de suas particularidades no âmbito do puro sujeito do conhecer, assimilando-a à concepção de gênio na filosofia de Schopenhauer.

\section{O GÊNIO ENQUANTO PURO SUJEITO DO CONHECIMENTO}

No puro sujeito do conhecer, encontra-se o artista, mas não o artista comum, e sim uma categoria muito particular: o gênio, pois é a ideia que ele almeja e, sua manifestação é exclusivamente artística. O puro sujeito do conhecimento possui duas acepções: (i) a primeira enquanto artista ou gênio; e (ii) enquanto espectador da obra de arte. Como "artista nos deixa olhar com seus olhos para o mundo. Que ele possua tais olhos, a 
desvelar-lhe o essencial das coisas, independentemente de suas relações, eis aí precisamente o dom do gênio, o que lhe é inato" (SCHOPENHAUER, 2005, p.265). Por isso, encontramos no artista a capacidade de contemplação do essencial que, a rigor, é alcançado pela "força descomunal de seu intelecto aliada a uma imaginação poderosa que revela a verdade das coisas" (CACCIOLA, 2004, p.174). A partir disto se evidencia que o artista genial procura sempre a ideia e nos permite olhar a ideia mediante seus olhos.

$\mathrm{O}$ artista enquanto gênio tem por objeto a ideia conforme seu "grau mais elevado e a duração mais prolongada daquele modo de conhecimento" (SCHOPENHAUER, 2003, p.84). Seu modo não segue o princípio de razão suficiente, pois se configura na forma mais plena de conhecer das coisas do mundo. Nesse sentido, o artista intui a ideia e simultaneamente frui o belo como suspensão de seu querer enquanto indivíduo. Dessa forma, o artista genial encontra-se em meio ao conhecer artístico, visto ser um puro sujeito do conhecimento que mantém a ideia fixa na contemplação. Assim, o artista genial "comunica aos outros a ideia apreendida" (SCHOPENHAUER, 2003, p.84). Em outras palavras, ele concebe a ideia no âmago próprio do conhecer artístico contemplativo, nesse caso é justamente pela intermediação de seu espírito de artista que a ideia aparece purificada e isolada de todo elemento estranho ao espectador da obra de arte. Por esse motivo, a essência do artista de gênio encontra-se na capacidade contemplativa da ideia que permite ao artista genial expor a ideia contemplada em sua obra:

\begin{abstract}
A essência do gênio consiste justamente na capacidade preponderante para tal contemplação. Ora, visto que só o gênio é capaz de um esquecimento completo da própria pessoa e de suas relações, segue se que a GENIALIDADE nada é senão a OBJETIDADE mais perfeita, ou seja, orientação objetiva do espírito, oposição á subjetiva que vai de par com a própria pessoa, isto é, com a vontade. Por consequência, a genialidade é a capacidade de proceder de maneira puramente intuitiva, de perder-se na intuição e afastar por inteiro dos olhos o conhecimento que existe originariamente apenas a serviço da//vontade-ou seja, de seu interesse, querer e fins - fazendo assim a personalidade ausentar-se completamente por um tempo, restando apenas o PURO SUJEITO QUE CONHECE, claro olho cósmico (SCHOPENHAUER, 2005, p.254).
\end{abstract}

Esta determinação da essência do gênio se encontra na capacidade do gênio de elevar-se do conhecimento submetido à vontade, dado que o conhecimento do gênio supera em qualidades um conhecer comum. Por esse motivo, "genialidade significa excesso de intelecto sobre a vontade" (BARBOZA,1997, p.63). Nesse sentido, o gênio se 
distingue por um conhecimento em demasia, na medida em que suas potencialidades vão além de um indivíduo comum. Por este motivo, "a fisiologia poderia, em sentido estrito, computar um tal excesso de atividade cerebral, e com ela do cérebro mesmo, em certa medida entre monstris per excessum" (SCHOPENHAUER, 2015, p.452). Assim, na genialidade as qualidades são excessivas e sua atividade cerebral mais elevada. Em termos mais específicos, poderíamos dizer que "se o ser humano normal consiste de $2 / 3$ de vontade e 1/3 de intelecto, o gênio, ao contrário, consiste em $2 / 3$ de intelecto e 1/3 de vontade" (SCHOPENHAUER, 2015, p.453). A partir disto se evidencia que, no homem de gênio, o intelecto possui mais força, e a vontade perde sua intensidade. Assim, no gênio, "o conhecimento, em toda a sua energia, assumiu a pura orientação objetiva, e o objeto é claramente concebido conforme a sua essência mais íntima" (SCHOPENHAUER, 2003, p.62).

Dessa forma, a genialidade ocorre devido à capacidade de acesso imediato à ideia que possibilita a sua condição distinta, visto que a sua atividade intelectual é desprendida para tal contemplação. Por isso, Schopenhauer reafirma que na contemplação da ideia há "pura disposição objetiva, isto é, um esquecimento completo da própria pessoa e de suas relações; por conseguinte, a genialidade nada é senão a objetidade mais perfeita, ou seja, orientação objetiva do espírito" (SCHOPENHAUER, 2003, p.61). No ato contemplativo, o gênio suspende sua individualidade, haja vista que sua atividade genial é desinteressada, pois se torna livre da vontade enquanto, sua disposição é puramente objetiva e inspiradora. $\mathrm{O}$ gênio não serve às relações causais do conhecimento, pois rompe com o conhecimento subordinado à cadeia causal e o supera.

Outra característica elementar do gênio é a busca da originalidade a partir da inspiração e do entusiasmo. Por isso sempre se "considerou o fazer-efeito da pessoa de gênio como uma inspiração [...] como o fazer-efeito de um ser supra-humano diferente do próprio indivíduo e que apenas periodicamente se apossa dele" (SCHOPENHAUER, 2005, p.258). Na inspiração genial, podemos observar a vivacidade do artista na busca por mais uma ideia a ser contemplada. No âmbito da inspiração genial, ora há um estado de absorção onírica, ora de excitação nervosa (Cf. SCHOPENHAUER, 2003, p.63). No gênio podemos observar quando há uma exaltação do intelecto, isto é, uma preponderância do cérebro na procura de ideias novas. Nas palavras de Schopenhauer, o que chamamos de: 


\begin{abstract}
o despertar do gênio, a hora da inspiração, o momento do entusiasmo nada mais é senão o tornar-se livre do intelecto quando abandonando momentaneamente o serviço da vontade, não mergulha na inatividade ou apatia, mas por instantes devém ativo de maneira totalmente solitária e espontânea (SCHOPENHAUER, 2015, p.455-456).
\end{abstract}

Esse é o instante do entusiasmo, da inspiração, que consiste na liberdade intelectiva. Nesse momento, "todos os tormentos do querer são, de imediato, de uma maneira maravilhosa, acalmados" (SCHOPENHAUER, 2005, p.268). Isso acontece pelo fato do gênio conhecer de forma contemplativa e conceber a ideia a partir de sua inspiração como artista. Como artista de gênio, está sempre à procura de ideias novas, já que sua característica é a busca pela originalidade. Seu interesse é constante e seu alvo são as ideias. Se no âmbito da individualidade os indivíduos "concebem um campo de trigo apenas como local onde se produz a matéria-prima do pão, um gênio como Van Gogh o toma como fonte inspiradora de um dos seus quadros imortais, o Campo de trigo com corvos" (BARBOZA,1997, p.64).

Essa é a capacidade do gênio, isso porque o gênio, além de contemplar a ideia em sua forma objetiva, possui a capacidade de produzir a ideia contemplada na forma de arte. A maneira como isso acontece ocorre devido ao artista de gênio "possuir um grau mais elevado e a duração mais prolongada daquele modo de conhecimento" (SCHOPENHAUER, 2003, p.84). Nesse sentido, o gênio toma a ideia apreendida para si e a produz no mundo. Dito com outras palavras, o gênio possui a capacidade de realizar a ideia. Nesse sentido, o gênio torna a ideia comunicável, sua competência reside na habilidade de pôr diante do outro a ideia apreendida na contemplação. Assim, na "obra de arte o gênio comunica aos outros a ideia apreendida. Na medida em que a ideia é apreendida pelos outros pelo medium facilitador da obra de arte" (SCHOPENHAUER, 2003, p.84).

Nesse aspecto, o gênio enquanto comunicador do conhecimento conforta o espectador, pois proporciona a este último uma paz momentânea no ato contemplativo. Dessa forma, a vontade do espectador é suspendida na quietude do contemplar da ideia. Assim, o gênio transmite a ideia ao espectador proporcionando a ele a condição de puro sujeito do conhecer. Enquanto contemplador, o espectador intui a ideia exposta pelo gênio, elevando-se ao conhecimento puro. $\mathrm{O}$ artista de gênio proporciona ao espectador 
um momento distinto, um instante de conhecimento estético. Esse conhecimento é concebido pelo espectador que apreende a realização da ideia na bela obra de arte.

\section{CONSIDERAÇÕES FINAIS}

Assim, a arte se configura como modo distinto de conhecimento na filosofia de Schopenhauer, pois proporciona ao indivíduo um conhecimento puro ideacional. Esse conhecimento ideacional não subordinado à vontade e independente do princípio de razão é que proporciona a arte se distinguir do conhecimento científico. Se no modo de conhecer científico conhecemos a partir do princípio de razão subordinado à vontade, na arte conhecemos a ideia independente do princípio de razão e livre do julgo da vontade. Em outros termos, a comunicação artística proporciona um conhecimento puro, que possibilita ao indivíduo ser conduzido através da arte a condição de puro sujeito do conhecimento.

No que concerne a mudança do indivíduo no ato do conhecimento contemplativo, verificou-se que está se dá por meio da intuição de maneira imediata, e que agora ele indivíduo passa a instância de puro sujeito do conhecer, onde este não conhece mais o objeto submetido à vontade e ao sofrimento mais sim a ideia. Acontece que o conhecimento artístico é intuitivo e o conhecimento científico é discursivo. Assim, em meio a este ato de conhecer contemplativo, ele puro sujeito e seu correlato a ideia mantêm-se em pleno equilíbrio.

Em linhas gerais, o puro sujeito é aquele que apreende a ideia, seja como artista de gênio ou espectador. Assim, tanto o espectador como artista são puro sujeito do conhecimento, pois ambos contemplam a ideia e tem na arte os seus sentimentos modificados. Acontece que "artista nos deixa olhar com seus olhos para o mundo. Que ele possua tais olhos, a desvelar-lhe o essencial das coisas, independentemente de suas relações, eis aí precisamente o dom do gênio, o que lhe é inato" (SCHOPENHAUER, 2005, p.265). Nesse sentido, o artista possui a particularidade de contemplar a ideia e executar através de uma técnica construtiva a ideia aprendida. Cada ideia contemplada pelo artista é possível de ser executada e realizada em obras de artes que proporcionam ao espectador contemplar a ideia que o artista apreendeu. Portanto, o puro sujeito do conhecimento possui as duas acepções analisadas: (i) a primeira enquanto artista ou 
gênio; e (ii) enquanto espectador da obra de arte. Todavia, o que difere o puro sujeito artista do puro sujeito espectador é que o primeiro é um artífice que cria a arte a partir da ideia contemplada, já o segundo contempla a ideia que o artista lhe proporcionou contemplar na obra de arte exposta pelo artista.

\section{REFERÊNCIAS BIBLIOGRÁFICAS}

BARBOZA, J. A decifração do enigma do mundo. - São Paulo: Editora: Moderna, 1997.

BARBOZA, J. Infinitude subjetiva e estética: natureza e arte em Schelling e Schopenhauer. São Paulo: Ed. UNESP, 2005.

CACCIOLA, M. L. O conceito de interesse. Cadernos De Filosofia Alemã: Crítica e Modernidade, (5), 05-15, 1999.

CACCIOLA, M.L. O intuitivo e o abstrato na filosofia de Schopenhauer. In. SILVA, J. C. S. P. da. Schopenhauer e o idealismo alemão/João Carlos Salles da (org.). Salvador: Quarteto, 2004.

SCHOPENHAUER, A. O Mundo como Vontade e como Representação. Tomo I; tradução. Apresentação, notas e índices de Jair Barboza. - São Paulo: Editora UNESP, 2005 .

SCHOPENHAUER, A. O Mundo como Vontade e como Representação. Tomo II; tradução. Apresentação, notas e índices de Jair Barboza. - São Paulo: Editora UNESP, 2015.

SCHOPENHAUER, A. Metafísica do Belo. Tradução, apresentação e notas de Jair Barboza. São Paulo: Ed. UNESP, 2003. 